\title{
Retraction Note to: Review on Tribological Performance of Natural Fibre-Reinforced Polymer Composites
}

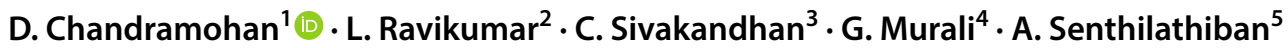

Published online: 2 May 2019

(c) Springer Nature Switzerland AG 2019

\section{Retraction to: Journal of Bio- and Tribo-Corrosion (2018) 4:55 https://doi.org/10.1007/s40735-018-0172-x}

The authors have retracted this article [1] due to significant overlap with a published book chapter [2]. All authors agree to this retraction.

\section{References}

1. Chandramohan D, Ravikumar L, Sivakandhan C et al (2018) J Bio Tribo Corros (2018) 4:55. https://doi.org/10.1007/s4073 5-018-0172-x
2. Nirmal U, Devadas A, Ahmad MM, Yuhazri MY (2018) A review on tribological performance of polymeric composites based on natural fibres. In: Kahn A et al (eds) Thermoset composites: preparation, properties and applications. Materials Research Forum LLC, Millersville, pp 300-340. https://doi.org/10.21741/97819 45291876-10

Publisher's Note Springer Nature remains neutral with regard to jurisdictional claims in published maps and institutional affiliations.

The original article can be found online at https://doi.org/10.1007/ s40735-018-0172-x.

D. Chandramohan

mail_2_cm@yahoo.com

1 Department of Mechanical Engineering, St Peter's Institute of Higher Education and Research, Chennai,

Tamil Nadu 600054, India

2 Department of Mechanical Engineering, Sri Sairam Engineering College, Chennai, Tamil Nadu 600044, India

3 Department of Mechanical Engineering, Sri Indu Institute of Engineering and Technology, Hyderabad, Telangana 501510, India

4 Department of Mechanical Engineering, Koneru Lakshmaiah Education Foundation, Vaddeswaram, Guntur (Dt), Andhra Pradesh 522502, India

5 Department of Mechanical Engineering, Apollo Engineering College, Chennai, Tamil Nadu 602103, India 